\title{
Conservation of Archaeological Limestone False Doors Applied on a Door No. 1755 at Atfiyah Museum Store - Egypt
}

\author{
Rabea Radi Abdel Kader ${ }^{1}$, Shaimaa Sayed Mohamed El-Sayed ${ }^{2, *}$ \\ ${ }^{1}$ Presidential Museums and Palaces Restoration Authority, Ministry of Antiquities, Cairo, Egypt \\ ${ }^{2}$ Conservation Department, Faculty of Archaeology, South Valley University, Luxor, Egypt
}

Email address:

Egyptianconservators2013@gmail.com (S. S. M. El-Sayed)

${ }^{*}$ Corresponding author

\section{To cite this article:}

Rabea Radi Abdel Kader, Shaimaa Sayed Mohamed El-Sayed. Conservation of Archaeological Limestone False Doors Applied on a Door No. 1755 at Atfiyah Museum Store - Egypt. Arabic Language, Literature \& Culture. Vol. 4, No. 1, 2019, pp. 16-20.

doi: $10.11648 /$ j.allc. 20190401.12

Received: February 13, 2019; Accepted: March 19, 2019; Published: May 15, 2019

\begin{abstract}
Stone false doors are considered one of history writing resources, within them, a lot of topics belonged to ancient Egyptian religious rites can be described, some of them contains inscriptions depict sacrifice forms of Egyptian gods and goddess, and with the false door, dead's soul can entre and go out between the world of living and the dead, there are a lot of limestone objects stored at Atfiyah museum store - Ministry of Antiquities - Egypt which known for the archaeologists as (Ali El-Kholy museum store), these objects exposed to many deterioration factors that threaten them especially the false doors. The research aims to shed the light on one of limestone false doors (no. 1755), samples were taken to identify the components and deterioration phenomenon, examined and analyzed to set a tight plan of conservation processes, first, mechanical and chemical cleaning were done to remove dust and clay deposits, then the weak surface were consolidated to save the important inscriptions.
\end{abstract}

Keywords: Conservation, Archaeological Limestone False Doors, Atfiyah Museum Store, Cleaning, Inscriptions, Cultural Heritage

\section{Introduction}

The selected limestone false door is one of a group of stone objects stored at Atfiyah museum store and returns to old kingdom era in the Egyptian history, Abdel Hamid Zayed is the excavator of these stone objects in the 1960s at El Shawaf archaeological site - Giza, from this period till now, the group is stored at its current place [1-5].

The selected false door was made of limestone, it's a chemical sedimentary rock with hardness (3) according to Moh's scale of hardness, it deposited in lakes, seas and other marine areas, the most important thing which is distinctive of sedimentary rocks is bedding layers [6-15].

False doors are architectural units with religious purposes, they were used at tombs and funerary temples in the most of ancient Egyptian ages, the main purpose was to permit the soul of dead to go in and go out of his tomb from the Ancient era through the ancient Egypt history [16]. Archaeological documentation of the case study:

1. Number of the false door at Atfiyah archaeological records: 1755.

2. Storing place: Atfiyah museum store - Ministry of Antiquities - Egypt.

3. Excavator: Abdel Hamid Zayed - Senior of Archaeologists at middle Egypt in the 1960s.

4. Excavation site: El-Shawaf archaeological site - Giza

5. Archaeological description of the door: Apart of Hieroglyphic inscriptions of a false door with irregular dimensions, at the upper side of the inscriptions, there are remains of view for a man or a woman sitting on a seat, the man probably called " mry Issi".

The selected false door dimensions: $32 \mathrm{~cm} \times 39.5 \mathrm{~cm}$.

Photographic Documentation

The selected false door is photographically documented before and after conservation processes, the deterioration phenomena diagnosed as follows: 
1. Dust and clay deposits.

2. Limestone weakness.

3. Writing a number with black ink-(Figure 1).

\section{Methodology}

A sample of limestone (from invisible area) was taken to identify the components, and deterioration phenomena using examination and analysis methods as follows:

\subsection{Scanning Electron Microscope (SEM)}

The stone sample was examined using SEM with magnification power $(1000 \times)$, to identify surface's internal texture and evaluate decay stage of minerals crystals-(Figure 2).

\subsection{Elementary Analysis Using EDAX}

EDAX refers to Energy Dispersive X-ray Analysis, it's an elementary analysis unit attached to SEM, stone sample was analyzed to identify mineral elements and their porpotion. (Figure 3)- (Table 1).

\subsection{Polarizing Microscope Examination}

Thin section of the stone sample was made to examin it under polarizing microscope in the existence of both polarizer and analyzer, and the absence of analyzer, from the crystals shape and their optical properties, mineral components can be identified, also deterioration phenomena. (Figures 4-5)

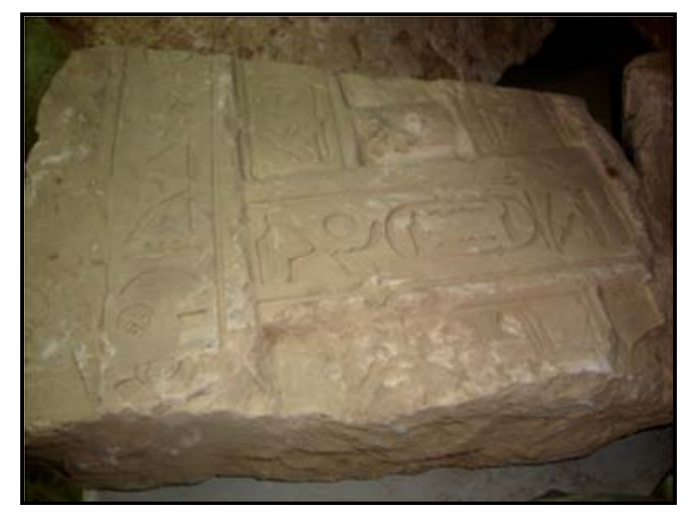

Figure 1. Selected False door no. 1755 at Atfiyah museum store.

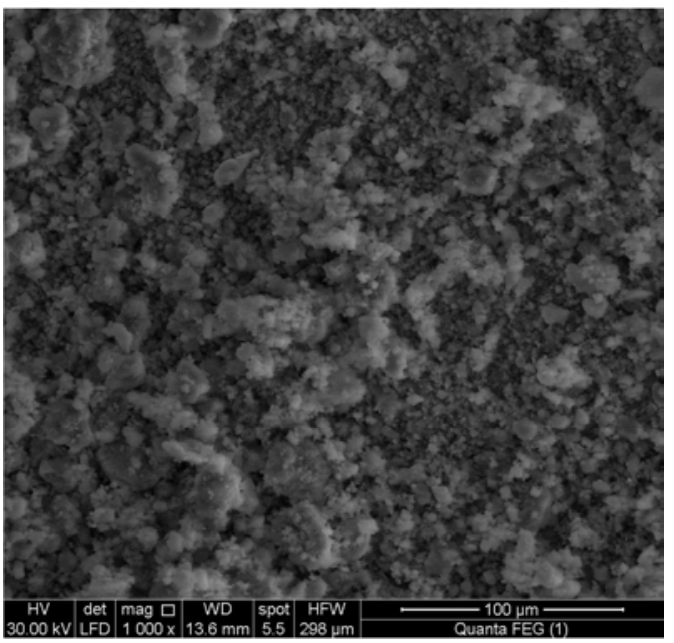

Figure 2. Stone sample examination by (Scanning Electron Microscope) (1000x mag).

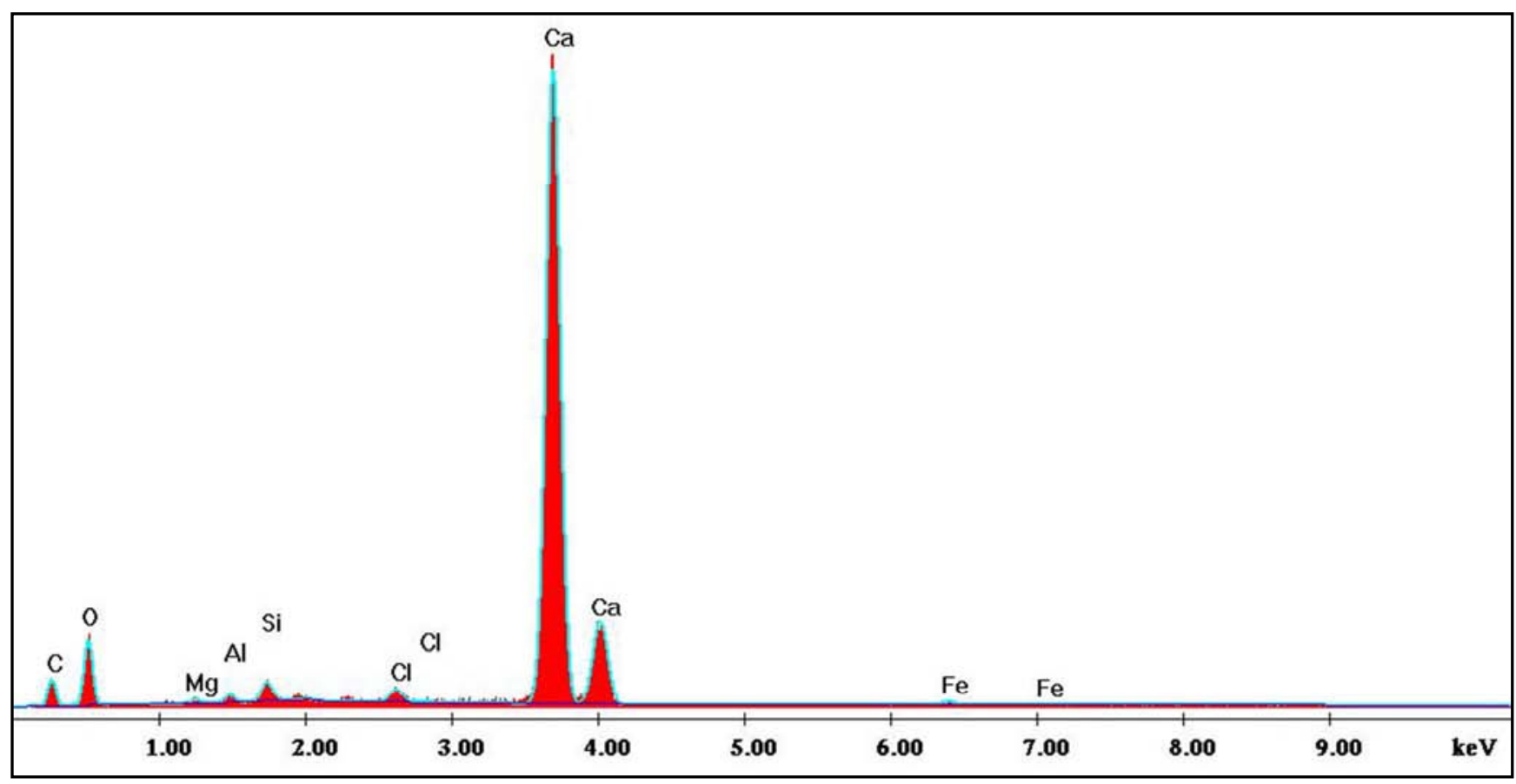

Figure 3. Elementary analysis of stone sample by EDAX. 
Table 1. Shows mineral elements and their proportion of stone sample.

\begin{tabular}{llllll}
\hline Elements & Wt \% & At \% & K-Ratio & Z & A \\
\hline C K & 9.76 & 18.18 & 0.0331 & 1.0417 & 0.3255 \\
O K & 36.67 & 51.27 & 0.0390 & 1.0270 & 0.1034 \\
Mg K & 0.51 & 0.47 & 0.0016 & 0.9899 & 0.3203 \\
Al K & 0.65 & 0.54 & 0.0028 & 0.9618 & 0.4476 \\
Si K & 1.46 & 1.16 & 0.0085 & 0.9908 & 0.5829 \\
Cl K & 0.82 & 0.52 & 0.0072 & 0.9431 & 0.8851 \\
Ca K & 49.36 & 27.55 & 0.4762 & 0.9645 & 0.9996 \\
Fe K & 0.77 & 0.31 & 0.0063 & 0.8906 & 1.0033 \\
Total & 100.00 & 100.00 & & & 0.9205 \\
\hline
\end{tabular}

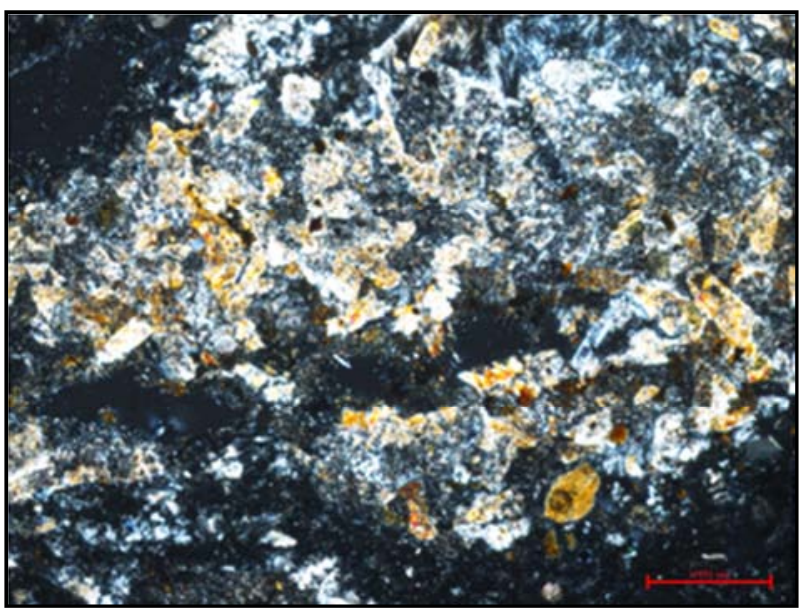

Figure 4. Examination of stone sample using polarizing microscope (the existence of both polarizer and analyzer).

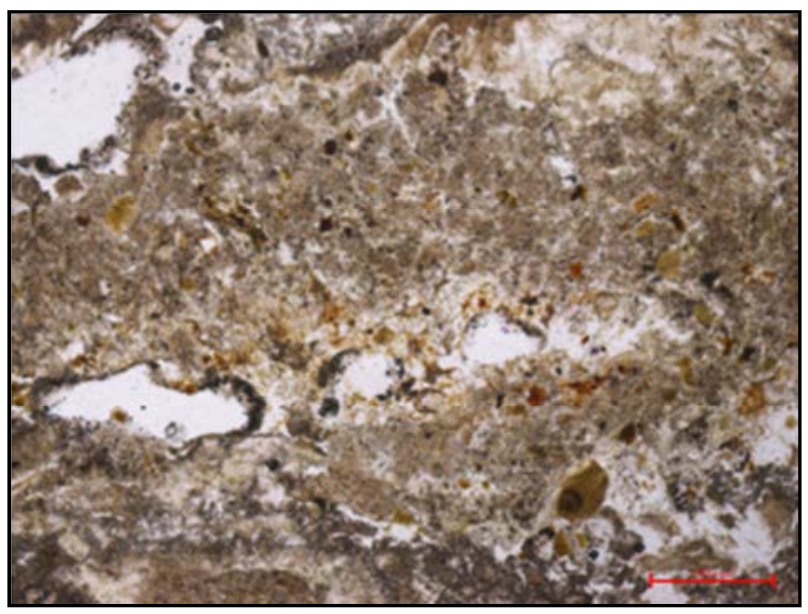

Figure 5. Examination of stone sample using polarizing microscope (the absence analyzer).

\subsection{The Conservation Processes of the Selected False Door No. 1755}

\subsubsection{Cleaning Processes}

First, dust and clay deposits were cleaned mechanically by brushes, scalpels and wooden toothpicks, then, the remains of them were cleaned chemically by a solution of acetone and distilled water 1:1, afterthat, the surface was washed using distilled water only to remove the previous solution remains. (Figure 6), there was a diffculty to remove the recording number which was written with black ink.

\subsubsection{Consolidation Processes}

The selected object was consolidated by Wacker $(\mathrm{OH}) 100$ diluted with ethyl alcohol in percentage $3 \%$ in five consolidation cycles (with the wait of dryness of every consolidation cycle before the application of which followed), the false door was left for 24 hours between consolidation cycles, the consolidation method was by brushing, the purpose of consolidation processes to improve the weak surface and save false door valuable inscriptions. (Figures 7-9).

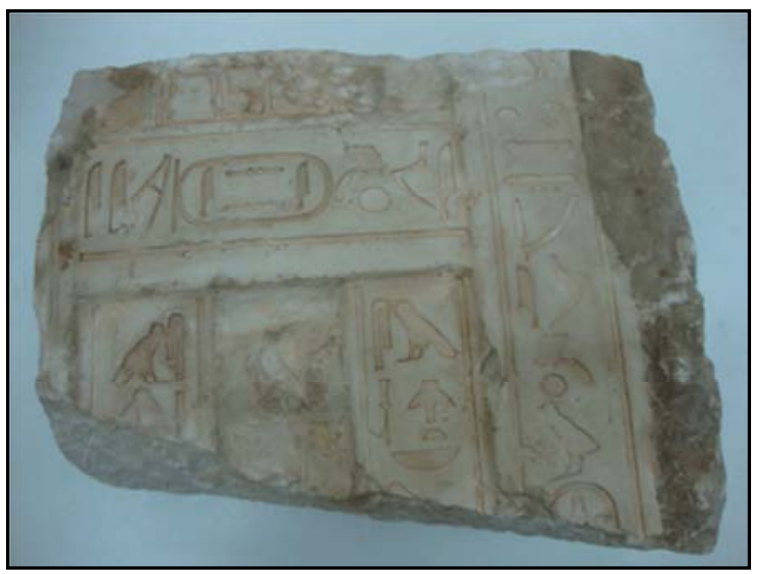

Figure 6. Limestone false door no. 1755 during cleaning processes.

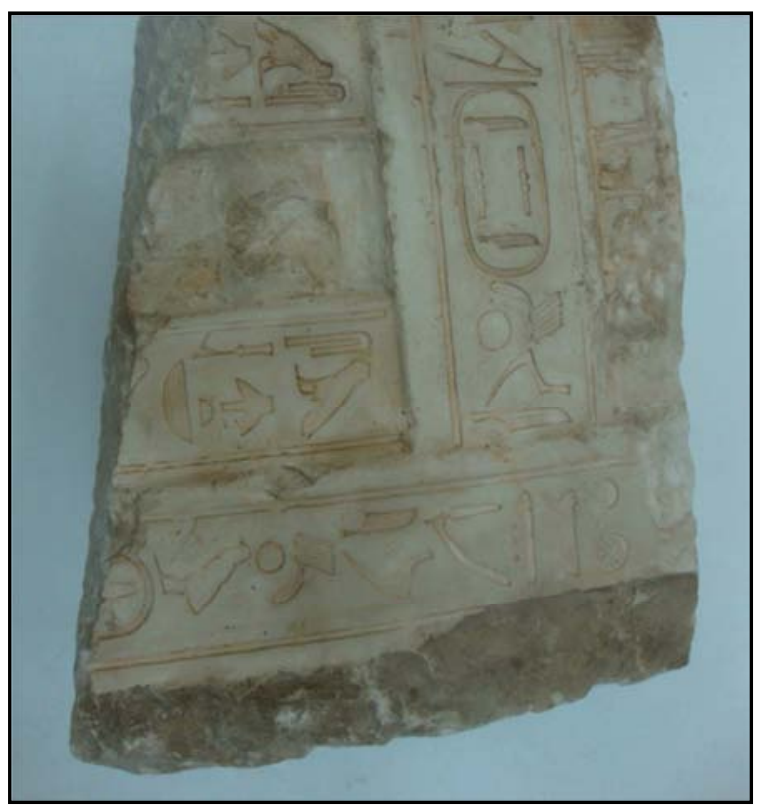

Figure 7. Selected false door after consolidation cycles. 


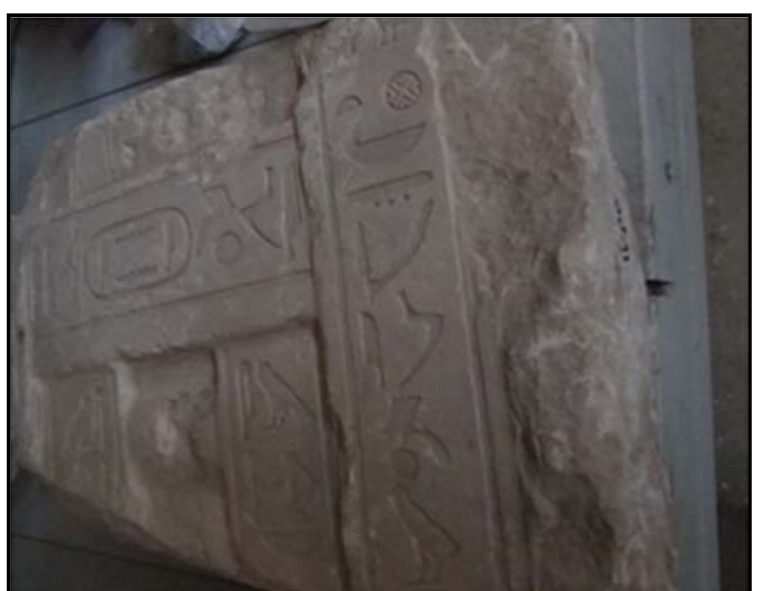

Figure 8. False door no. 1755 before conservation processes.

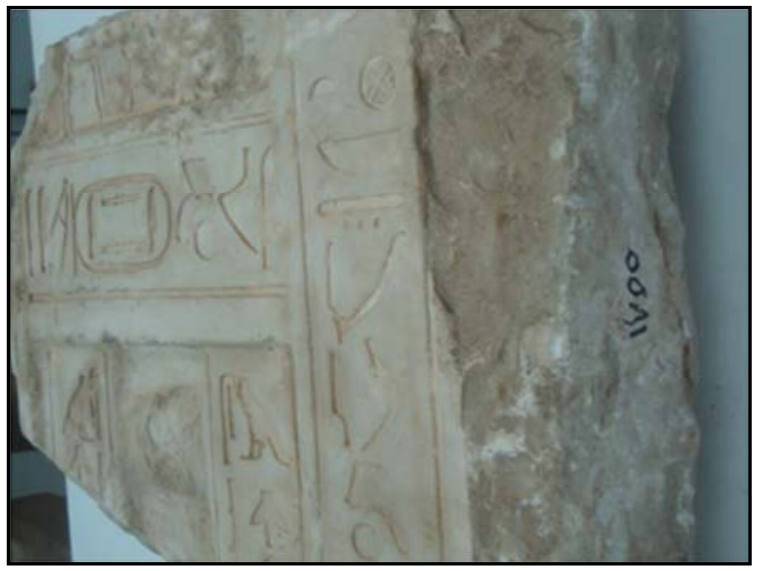

Figure 9. False door no. 1755 after conservation processes.

\section{Results and Discussion}

From examination and analysis of the stone sample taken from the selected false door, EDAX results are: the basic component of limestone is calcite (calcium carbonates) because of high percentages of $\mathrm{Ca}$ and $\mathrm{C}$, also, there are clay minerals because of the existence of $\mathrm{Al}, \mathrm{Mg}, \mathrm{Si}$ as elements, and also, there are quartz and some ferrous minerals (the existence of $\mathrm{Si}$, fe). Clay minerals, quartz and ferrous minerals are traces in the sample, there is probably an effect of burial soil because of $\mathrm{Cl}$ existence in the sample.

SEM examination shows that the surface is weak and needed to be consolidated, it is obvious from the magnification of internal texture $(1000 \times)$.

Polarizing microscope examination confirns the elementary analysis results (EDAX), there are many crystals of calcite, also crystals of clay minerals, quartz and ferrous minerals as traces (in the existence of both polarizer and analyzer and the absence of analyzer).

\section{Conclusion}

The false doors were used in Ancient Egypt at tombs for funeral purposes to serve the dead in his eternal life, at Atfiyah museum store - ministry of Antiquities - Egypt, there are many stone panels and false doors that were excavated in the 1960s at El-Shawaf excavation site - Giza, they were stored from this period till now at their current place without any conservation processes and their valuable views became weak, the false door no. 1755 were selected to become as acase study because the surface was weak and needed to be cleaned and consolidated.

First, a sample was taken, then examined and analyzed to identify components and deterioration phenomena, afterthat, the conservation processes was done to save this door and its precious views.

The researchers recommend to store the door no. 1755 in an ideal storing environment (Air temperature $18-22^{\circ} \mathrm{C}$ and relative humidity $45-55 \%$ away from dust, air pollution gases, microorganisms and insects) also, not to write any recording numbers using inks on the monuments.

\section{Acknowledgements}

To Mr / Ahmed Khalil Rashid - Manager of Atfiyah museum store - Ministry of Antiquities - Egypt for his great efforts exerted with us.

\section{References}

[1] Mission égypto-française d'Atfih, 'Atfih, la nécropole des vaches sacrées (mission 2008), Institut d' Egyptologie Francois Daumas, Universite Paul Valery, France, 2008.

[2] Shaimaa Sayed Mohamed El-Sayed Mahgoub, ' Evaluation of Wild and Domestic Trees and Plants Hazards, their Role in the Deterioration of Archaeological Buildings Ruins, Methods of Treatment and Assessment of these Hazards Applied on a Chosen Historical Building and Site ', PhD thesis, Restoration department, Faculty of Archaeology, Cairo University, Egypt, 2015/2016.

[3] Rabea Radi Abdel Kader, Abdel Hamid Kafafy, Shaimaa Sayed Mohamed El-Sayed, Identification of Groundwater's Type in Sarabium Archaeological Site - Atfiyah - Egypt and Its Microbiological Effect, International Journal of Archaeology. Vol. 4, No. 5, 2016.

[4] Rabea Radi Abdel Kader, Shaimaa Sayed Mohamed El-Sayed, The Agricultural Environment's Effect on the Deterioration of the Archaeological Sites Applied on Atfiyah's Sarabium Archaeological Site - Egypt, International Journal of Archaeology, Vol. 5, No. 1, 2017.

[5] Rabea Radi Abdel Kader, Shaimaa Sayed Mohamed El-Sayed, El-Ghareeb Sonbol, Marine Environment's Effect on the Deterioration of Archaeological Buildings in the Mediterranean Sea Coast (Alexandria - Egypt as an Example). International Journal of Archaeology, Vol. 5, No. 2, 2017.

[6] Roby, T., "Overcoming the crisis in mosaic conservation", AIA site preservation program, Archaeological Institute of America, U.S.A.

[7] Radi, R., \& Sayed, Sh., "The Study of ground water effect and risks on the safety of the archaeological Islamic buildings in Egypt applied on Azabk El - Youssefi Madrasa", Built Heritage 2013 Monitoring Conservation Management Conference (BH 2013), Italy, 18-20 November 2013. 
[8] Jones, L. K., "Caring for archaeological sites - practical guidelines for protecting and managing archaeological sites in New Zealand ", Science \& Technical Publishing, Department of Conservation Tepapa Atawbai, New Zealand, 2007.

[9] Honeyborne, B. D., "Weathering and decay of masonry "in" conservation of building and decorative stone", first publish, Butterworth Heinemann, Great Britain, 1990.

[10] Brier, B., "The History of Ancient Egypt", Part II, The Teaching company limited partnership, USA, 1999.

[11] Charola, A. E., \& Herodotus, "salts in the deterioration of porous materials: An overview", Jaic, volume 39, number 3, article 2, May 2000.

[12] Torok, A., "surface strength and mineralogy of weathering crusts on lime stone buildings in Budapest", building and environment magazine, Germany, 2003.
[13] Oliver, A., "dampness in buildings", BSP publishers, 1998.

[14] Alden, A., "about sedimentary rocks", The New York times company, New York, 2010.

[15] Croft, A. W., "adhesives and coatings", the conservation unit of the museums \& galleries commission in conjunction with Routledge, London, 1993.

[16] Samar Rabea Mohamed Abd-Elgawad, "Study of deterioration phenomena, treatment and conservation of the stone false doors in some old kingdom tombs at Sakkara applied on one of the selected models", Master thesis, Conservation department, Faculty of Archaeology, Fayoum University, Egypt, 2017. 